Resenha

\title{
O Introspeccionismo ainda não Considerado: O Caso de Edward Titchener
}

\author{
The Philosophical Background and Scientific Legacy of E. B. Titchener's Psychology: Understanding Introspectionism \\ Christian Beenfeldt \\ New York, NY: Springer, 2013, 74p.
}

Cíntia Fernandes Marcellos ${ }^{\mathrm{I}}$

Programa de Pós-Graduação em Psicologia da Universidade Federal de Juiz de Fora (Juiz de Fora), Brasil

Com o propósito de "reabrir e reescrever" um importante capítulo da história da psicologia, superando a chamada história mítica ou ficcional da área, conforme as discussóes de Allan Costall (2006) e Thomas Leahey (1992), Christian Beenfeldt apresenta sua obra The Philosophical Background and Scientific Legacy of E. B. Titchener's Psychology: Understanding Introspectionism, um dos mais recentes volumes da série Springer Briefs in Philosophy.

Adotando como ponto de partida para sua crítica a interpretação segundo a qual a psicologia como ciência da vida mental, baseada na introspecçáo, teria sido superada pelo behaviorismo, e que esse movimento, por sua vez, teria visto sua restrita agenda de pesquisa desafiada pela revolução cognitiva, responsável pela restauração do estudo da mente com base em novos recursos, Beenfeldt (2013) assume o considerável compromisso de "oferecer uma reconceitualização fundamental do introspeccionismo Titcheneriano com respeito a sua postura científica e filosófica básica, sua metodologia investigativa e a causa efetiva de sua recusa" (p. XI).

A tese defendida pelo autor é a de que o introspeccionismo de Titchener não é, ao contrário do que afirma a interpretaçáo tradicional, um sistema fundamentado pela introspecção, mas sim por pressupostos do associacionismo britânico e pelo método analítico, ao passo que o motivo para sua ruína estaria relacionado à intrusão desses mesmos pressupostos em sua abordagem experimental.

$\mathrm{O}$ autor organiza sua argumentação em três partes, que correspondem à estrutura formal do livro. A primeira é dedicada à análise do background intelectual de Titchener e apresenta aspectos característicos do associacionismo britânico em sua formulação inicial e amadurecida; a segunda parte discute o sistema introspeccionista do autor; e, na última, Beenfeldt (2013) assume a tarefa de demonstrar, ao longo de três capítulos, seu argumento de que o introspeccionismo é uma forma de associacionismo que "tinha muito pouco a ver com o que hoje reconheceríamos como introspecção" (p. XI).

A fim de oferecermos uma análise à altura dos objetivos de Beenfeldt, nos concentraremos nos argumentos do autor, destacando alguns aspectos metodológicos, cujas consequências consideramos importantes para a interpretação das ideias de Titchener. O primeiro ponto a ser observado surge ainda na introdução do livro, onde o autor nos apresenta seus objetivos.

Considerando que o introspeccionismo é mais uma criação do behaviorismo do que uma proclamaçấo de seus próprios adeptos, Beenfeldt adota o termo para se referir a um conjunto de psicologias experimentais influentes nos séculos XIX e XX e, em especial, à psicologia de Edward Titchener. Ele destaca que o verdadeiro problema do introspeccionismo está, contudo, em outro lugar: na suposição de sua relação fundamental e necessária com a introspecção. Embora apresente, em linhas gerais, qual é a concepção de introspeccionismo a ser defendida, Beenfeldt náo nos esclarece precisamente qual é a noção de introspecção que está em questão. Com isso, o autor comete o primeiro e talvez mais grave erro na defesa de sua argumentação, pois, ao criticar a leitura tradicional acerca do introspeccionismo, náo basta dizer o que ele é, conforme sua nova interpretação, mas é preciso também dizer aquilo que se defende que ele não é. Ironicamente, Beenfeldt parece ter ignorado a constatação feita por Costall (2006) acerca de uma questáo corriqueira na apresentação do tema, a de que "o problema, ao final, com os manuais, quando eles estão ensaiando a velha história sobre o fim da psicologia introspectiva, é que eles raramente se preocupam em explicar o que eles entendem por 'introspecção'" (p. 649).

As únicas e genéricas referências de Beenfeldt em relação ao significado de introspecção ao longo de todo o livro são mençóes àquilo que hoje seria re- 
conhecido como introspecção. Mas poderemos realmente adotar tal critério? Não seria essa uma avaliação exclusivamente presentista sobre o que deve ou não ser entendido como introspecção? Será essa hipotética concepção contemporânea idêntica à definição Titcheneriana? E igualmente ao longo de toda a sua obra? Essas questôes nos acompanharão ao menos até o terceiro capítulo, quando, nos promete o autor, encontraremos a demonstração de seus argumentos. Por ora, sigamos conforme a estrutura do livro.

Em seu primeiro capítulo, Beenfeldt indica seletivamente aspectos da tradição empirista britânica que, posteriormente, identificará no sistema de Titchener. Sua passagem por Thomas Hobbes, John Locke e David Hume tem como propósito identificar aqueles elementos que, juntos, configurariam as suposições fundamentais da fase inicial do associacionismo: o elementarismo, ou a doutrina segundo a qual sistemas complexos são formados por constituintes atômicos ou indivisíveis; o reducionismo decomposicional, que considera a análise de níveis mais complexos de organização em níveis cada vez mais simples, até o limite de suas configuraçôes elementares; o sensacionismo ou sensacionalismo, ou seja, a afirmação de que as sensações constituem as unidades mínimas da experiência humana; e, por fim, as leis de associação, que governariam a conexão entre os fenômenos mentais, garantindo sua expressão organizada e não casual.

No capítulo seguinte o autor apresenta o que considera ser a expressão elaborada desses pressupostos, encontrada nos trabalhos de David Hartley, James Mill e John Stuart Mill. Não obstante a sucinta apresentação das ideias desses três autores e das distinçôes entre eles, Beenfeldt defende haver neles uma abordagem que pode ser caracterizada como uma ciência física da vida mental, que apresenta um caráter elementarista, reducionista e sensacionalista, submetido a leis de associação e em estrita analogia com os fenômenos e as leis da física e da química. Tal abordagem configura, segundo Beenfeldt, a herança do associacionismo na psicologia e que, longe de ser positiva, constitui a seus olhos um equívoco, uma vez que revela uma extrapolação especulativa de conhecimentos legítimos de ciências como a física e a química para além de seus domínios.

Em sequência, seu objetivo na segunda parte do livro é considerar como essas ideias, herdadas da tradição associacionista, se fundiram com a ênfase na investigação experimental de laboratório ao longo do século XIX. Para isso, Beenfeldt opta por um caminho bastante tradicional, porém insuficientemente esclarecedor para o problema em questão: ele oferece, em seu terceiro capítulo, uma superficial apresentação do trabalho de Wilhelm Wundt (1832-1920) e de seu relacionamento com Titchener. Abstendose de tomar posição em relação às interpretaçôes tradicionais e modernas sobre Wundt e à responsabilidade de Titchener na distorção de suas ideias, Beenfeldt assume, sob uma curiosa justificativa, o que ele chama de imagem percebida de Wundt aquela que o considera um introspeccionista, cujas ideias eram próximas das de Titchener.

Segundo ele, tal opção deve-se ao fato de que é "esse estado de coisas, percebido naquele tempo, e subsequentemente, que é relevante em termos causais com respeito à teoria da introspecção dominante na psicologia" (Beenfeldt, 2013, p. 30). Também aqui se pode questionar o caminho percorrido pelo autor que, ao pretender oferecer uma reinterpretação tão fundamental sobre as ideias de Titchener, acompanha leituras tão tradicionais, quando não errôneas. A referência a Wundt cumpre um papel meramente figurativo no texto e suas ideias sobre a introspecção jamais são apresentadas, o que poderia ser esperado diante de sua citada importância para o assunto. Além disso, o autor passa da tradição mais estritamente filosófica britânica para o contexto científico-experimental de Wundt, sem reconhecer qualquer importância à variedade da formação de Titchener ainda na Inglaterra, como o seu treinamento experimental inicial, ou seu contato com outras perspectivas científicas e filosóficas, tanto em Oxford quanto em Leipzig.

É a partir dessas condiçóes que o capítulo quatro apresenta o sistema psicológico de Titchener ou, mais exatamente, aquilo que o autor delimitou como representativo desse sistema. Ignorando as discussôes e evidências acerca das transformaçóes nas ideias de Titchener, inclusive no que diz respeito exclusivamente à introspecçáo, Beenfeldt considera toda a sua obra como representativa de uma psicologia estruturalista, destacando entre suas características a analogia com a morfologia e o papel da análise. Convencido da influência dos propósitos reducionistas de Titchener e, para sustentar a interpretação de que seu sistema representaria uma química mental elementar, Beenfeldt parece deixar de lado a totalidade dos objetivos da psicologia apresentados pelo próprio autor, fazendo com que seu interesse em explicar a vida mental 
se mostre essencialmente reduzido à simples identificação e classificação de seus elementos constituintes, com a finalidade de construir uma verdadeira tabela periódica dos fenômenos psíquicos.

Tal postura torna-se ainda mais explícita quando o autor questiona a definição de processo defendida por Titchener e sua recusa da noção de átomos mentais. Segundo ele, a adoção dessa definição decorre de uma tentativa de desviar-se das críticas ao atomismo e de uma compreensão parcial dos aspectos microfísicos das ciências naturais, que teriam levado Titchener a desconsiderar que a distinção entre coisa e processo, isto é, entre algo permanente, relativamente inalterável e delimitável e algo em contínua operação e progressiva mudança, seria apenas aparente e restrita ao nível macroscópico. Desvelada essa "confusão terminológica" causada pelo próprio Titchener, Beenfeldt (2013) acredita ter demonstrado que a "insistência de Titchener na defesa dos processos mentais, como opostos aos átomos mentais, é de fato vazia" (p. 39). O que Beenfeldt desconsidera é que, nesse momento, o propósito central de Titchener é, mais do que simplesmente evitar as críticas dirigidas ao atomismo, eliminar a presença da qualquer hipótese substancialista sobre o mental, inclusive o reducionismo materialista, e assegurar a autonomia de uma ciência psicológica.

Com base em tais interpretaçóes, Beenfeldt ainda seleciona passagens das obras de Titchener que demonstrariam que os pressupostos do associacionismo compóem igualmente a agenda do introspeccionismo, concluindo que o sistema de Titchener nada mais é do que uma forma de associacionismo baseada em laboratório e que ele, por sua vez, é de fato um inglês representando a tradição britânica, e não a alemã, nos Estados Unidos.

Aqui, contudo, é necessário notar que não apenas a convicção do autor parece tê-lo levado a encontrar em Titchener as características que esperava como também a seleção aparentemente arbitrária de obras do autor é responsável pela constituição de falsas evidências. Ao enfatizar a formação britânica de Titchener, Beenfeldt seleciona passagens de sua obra que a confirmam, como as menções a James Mill e sua influência na adoção da introspecção, e a famosa passagem da primeira edição de An outline of psychology (1896), em que ele afirma que o "ponto de vista geral do livro é aquele da tradicional psicologia inglesa" (p. VI). Embora sejam autênticas essas passagens, Beenfeldt revela, contudo, desconhecer as alterações realizadas por Titchener nas ediçôes seguintes desse mesmo livro, como a retirada intencional dessa afirmação de vínculo com a psicologia inglesa, e em outras obras, nas quais Titchener demonstra uma postura diferente em relação a essas mesmas influências. Duas delas podem ser encontradas em textos citados pelo próprio Beenfeldt, como em The schema of introspection (1912), em que Titchener não apenas reconhece o caráter equívoco do termo "introspecção" mas também aceita a distinçâo entre sua forma direta, que envolve a apercepção do processo simultaneamente a sua ocorrência, e a indireta, que se refere à recuperaçáo de um processo já ocorrido por meio da memória. Outra passagem importante que sugere possíveis modificações na forma de Titchener conceber a introspecção está em $A$ beginner's psychology (1915), em que ele reafirma a influência de Mill em sua opçáo pelo caminho introspectivo, mas considera que "[...] todavia, muitos anos tiveram que passar antes que eu compreendesse devidamente o que ele tinha deixado fora dele" (p. VII). Curiosamente, nenhuma dessas passagens foi considerada na análise de Beenfeldt.

Com isso, chegamos à terceira e última parte do livro. Em seu quinto capítulo, Beenfeldt apresenta sua interpretação sobre o declínio do introspeccionismo. Primeiramente, ele afirma que ao referir-se à "introspecção experimental", "introspecção sistemática" ou apenas "introspecção", Titchener não queria dizer introspecção simplesmente, mas antes o que pode ser considerado como uma forma de investigação psicológica sistemática e fortemente carregada de pressupostos teóricos do associacionismo, a qual Beenfeldt chamará de "análise psicológica", "atenção analítica" ou apenas "análise".

Beenfeldt (2013) ainda lista algumas características do treinamento Titcheneriano, como a atenção e a concentração intensivas sobre o fenômeno, para concluir que esse método é tratado por Titchener como "um dispositivo expressamente projetado para realizar uma tarefa específica, produzir um tipo específico de dados para os quais ele foi projetado e calibrado previamente" (p. 51), garantindo assim a imunidade de seus pressupostos em relação à crítica. Uma evidência apontada por Beenfeldt para tal afirmação é a analogia usada por Titchener (1912) acerca dos limites da introspecção e os de um microscópio que igualmente podem observar apenas o que é observável. Embora Titchener utilize tal analogia para indicar que produtos da abstração lógica não podem ser observados empiri- 
camente, Beenfeldt (2013) a menciona para afirmar que "conforme a psicologia Titcheneriana, podemos observar apenas sensaçóes e afetos ou, mais exatamente, [...] compostos destes" (p. 52), demonstrando mais uma vez sua forçosa identificação de elementarismo ingênuo e estrito em Titchener.

Apesar disso, Beenfeldt (2013) alcança sua conclusão, a de que a análise psicológica de Titchener foi projetada para efetuar a "confirmação experimental da perspectiva empirista clássica acerca do mental” (p. 52). Com base nessa caracterização e em uma nota sobre o procedimento experimental autêntico, Beenfeldt (2013) sugere que a radical incompatibilidade entre o método adotado por Titchener e a introspecção, tal qual "filósofos, psicólogos e pessoas comuns" (p. 52) reconhecem hoje, consiste no fato de que o primeiro mantém seus pressupostos completamente imunes à refutação científica, enquanto os segundos não incorreriam nesse vício. Embora essa seja uma chave de discussão interessante e possível, que conduziria, em última instância, a uma discussão acerca do papel das pressuposiçóes teóricas nas ciências indutivas, o autor não a executa, restringindo-se a afirmaçôes categóricas.

Além disso, e, antes de passarmos ao ponto seguinte, há um importante lapso cometido por Beenfeldt em relação à definição de introspecção para Titchener. Ele afirma que a investigação realizada por Titchener consistia exclusivamente em uma retrospecção. Embora isso seja afirmado até certa época, seus trabalhos a partir da década de 1910 indicam que ele não estava plenamente satisfeito com essa situação e sua postura é reformulada. Titchener passa a considerar a retrospecção um procedimento para iniciantes e útil em apenas poucos casos, ao passo que a introspecção direta é adotada como o padrão universal em suas investigaçôes. Tal transformação aparece em ao menos duas das obras citadas por Beenfeldt, The text-book of psychology (1910, pp. 22-23) e The schema of introspection (1912, pp. 491-493), como já indicado acima, mas cujo conteúdo não foi notado por ele.

Outro aspecto importante diz respeito à defesa de Beenfeldt do papel da análise como verdadeiro qualificativo do método Titcheneriano. Seu argumento consiste na alegação de que, para Titchener, não apenas toda ciência começa com a análise, mas que este processo é o único método confiável da psicologia e a fonte por excelência de evidência acerca da vida psíquica. Contudo, mais uma vez Beenfeldt parece tomar a parte pelo todo e extrair dela uma conclusão categórica ${ }^{1}$. Titchener afirma que a ciência começa com a análise, mas não que se encerra nela. Segundo ele, a identificação da regularidade das conexôes entre os processos mentais e o estabelecimento de suas leis dependem essencialmente da segunda etapa de seu método introspectivo: a síntese dos elementos sob condiçôes experimentais. A essa etapa segue-se ainda a identificação das condiçôes fisiológicas paralelas aos processos mentais (Titchener, 1910), o que é substancialmente ignorado por Beenfeldt em prol de sua própria interpretação.

Os capítulos seis e sete são, por sua vez, apenas desdobramentos dessa leitura, nos quais Beenfeldt se permite explicar as falhas do introspeccionismo e os motivos para seu abandono. Dentre os "defeitos congênitos" do sistema, Beenfeldt cita a alegação de erro de estímulo em casos de resultados controversos e desfavoráveis, como o que envolveu a escola de Würzburg; a virtual destruição da experiência psíquica concreta em numerosas unidades elementares, jamais reconstituídas em sua forma original; a desconsideração da contribuição de outras áreas da psicologia, assim como por questóes de interesse das pessoas comuns; e, por fim, e mais surpreendentemente, a afirmação de que insights do Darwinismo e da biologia comparativa estiveram completamente ausentes do sistema introspeccionista, exclusivamente preocupado com os padróes da química inorgânica e da física Newtoniana. Segundo Beenfeldt (2013), a psicologia Titcheneriana permaneceu "essencialmente intocada pelo advento dos dados sobre a biologia humana e animal" (p. 66). Além dos aspectos já discutidos, tais afirmaçôes demonstram ainda o desconhecimento do autor em relação à literatura especializada e às informaçôes básicas acerca da biografia e da obra de Titchener, como a declarada influência de Herbert Spencer e Thomas Huxley, especialmente sobre a fase inicial de sua produção, suas próprias pesquisas em biologia comparada, e as relaçôes que sua psicologia assume com a biologia na explicação dos fenômenos mentais.

Por ora, a interpretaçáo de Beenfeldt (2013) sobre o fracasso do introspeccionismo reflete apenas seu

\footnotetext{
Na página 56, Beenfeldt reconhece o uso da síntese em An outline of psychology (1896), porém apenas como um procedimento para confirmação dos resultados encontrados pela análise, e não como etapa com função específica e positiva, o que já pode ser notado em A text-book of psychology (1910), outra obra citada pelo autor, nas páginas 36 a 41 .
} 
profundo compromisso com uma leitura cognitivista, mais especificamente a de Ulric Neisser, mencionada pelo autor, e que considera como os verdadeiros motivos para seu abandono a restrição ao uso em laboratório, não oferecendo nenhuma informação sobre a interação das pessoas com o mundo, e a ausência de uma teoria sobre o desenvolvimento cognitivo, os processos inconscientes e o comportamento.

Diante disso, não surpreende encontrar em seu capítulo final a constatação de que o introspeccionismo Titcheneriano foi um sistema especulativo, mais do que observacional, uma vez que todas as suas numerosas observações eram feitas para encontrar o que já presumiam existir de antemão, isto é, os elementos mentais. Dada a diferença que Beenfeldt (2013) acredita encontrar entre esse sistema e a introspecção, ele afirma que a insistência de Titchener no uso desse termo constituiu uma "estratégia epistêmica deliberada" (p. 72) de atribuir um novo sentido, o de análise psicológica, a um termo já velho e tradicional, a introspecção. Os motivos para isso são dificilmente alcançáveis.

Por fim, não obstante a publicação de novos estudos sobre Titchener já representar em si um motivo para comemoração, não se pode, contudo, considerar que o trabalho de Beenfeldt tenha lançado uma nova luz sobre a compreensão de suas ideias e, menos ainda, que tenha cumprido aquilo que prometeu. Os maiores responsá- veis por esse resultado parecem ter sido o insuficiente conhecimento acerca da totalidade da obra do autor e os problemas decorrentes de suas escolhas metodológicas. Assim, visto não ser possível aceitar a tese de Beenfeldt de que o sistema introspeccionista de Titchener não é baseado na introspecçáo, a maior, e talvez exclusiva, contribuição do trabalho de Beenfeldt é a constatação de que o introspeccionismo traz em si fortes influências da tradição associacionista, ainda que, como ele parece não ter notado, não sejam elas as únicas.

\section{Referências}

Costall, A. (2006). 'Introspectionism' and the mythical origins of scientific psychology. Consciousness and Cognition, 15(4), 634-654.

Leahey, T. H. (1992). The mythical revolutions of American psychology. American Psychologist, 47(2), 308-318.

Titchener, E. B. (1896). An outline of psychology. New York/London: The Macmillan \& Co.

Titchener, E. B. (1910). A text-book of psychology. New York: The Macmillan \& Co.

Titchener, E. B. (1912). The schema of introspection. The American Journal of Psychology, 23(4), 485-508.

Titchener, E. B. (1915). A beginner's psychology. New York: The Macmillan \& Co. 